\title{
Editorial
}

\section{O CENTENÁRIO DO DR. OSWALDO LANGE}

"ARQUIVOS DE NEURO-PSIQUIATRIA é o periódico oficial da Academia Brasileira de Neurologia e é publicado trimestralmente, com absoluta regularidade, desde sua criação em 1943 até o presente." - Esta sentença da página inicial de cada número deste periódico se completa com a menção de quem é a alma dele: o Dr. Oswaldo Lange. Ele criou a revista e a editou enquanto viveu. Este volume do periódico comemora o centenário dele, seu Editor Fundador. Este editorial reúne dados sobre sua vida e sua obra.

Duas pessoas nortearam a formação do Dr. Oswaldo Lange. Sua mãe, a farmacêutica Fany Lange, e Enjolras Vampré. Ela plasmou os traços de sua personalidade. Vampré, seu mestre, plasmou seu desempenho profissional. Professor de Neurologia da Faculdade de Medicina de São Paulo, ora Faculdade de Medicina da Universidade de São Paulo (FMUSP), Vampré o orientou na ciência e arte de ser médico e nos caminhos da neurologia desde quando, como acadêmico de medicina, em 1925 passou a frequentar a Clínica Neurológica da futura FMUSP. Da somatória dessas influências resultou sua figura séria, altiva e forte, continuada e disciplinadamente voltada ao trabalho e a construir com carinho, sempre um mestre. As virtudes que o caracterizaram se refletiram diretamente na vida de sua família - na de sua própria mãe; na de sua esposa, Adelina Filizola Lange; na de seus filhos, Marília Lange Spina França e Sérgio Lange; na de seus netos - e se refletiram também no desempenho de seus discípulos, através de toda sua existência. Nascido na cidade de São Paulo em 28 de agosto de 1903, nela sempre viveu até cessarem seus dias em 29 de agosto de 1986, quando completara 83 anos de idade.

Três aspectos sobressaem na obra de Oswaldo Lange: sua atuação como médico e professor de neurologia, seu desempenho em sociedades médicas, sua dedicação a este periódico, Arquivos de NeuroPsiquiatria. Como corolário, sua experiência como editor científico. Esses aspectos constam dos itens que seguem.

OSWALDO LANGE, O MÉDICO E O PROFESSOR UNIVERSITÁRIO

Desde quando se formou em 1927 na futura
FMUSP, o Dr. Oswaldo Lange passou a integrar o grupo dos colaboradores diretos de Vampré, que já contava com Adherbal Tolosa e Paulino Watt Longo. A partir de então desenvolve a prática e a pesquisa da aplicação clínica do exame do líquido cefalorraquidiano (LCR) alicerçadas na neurologia. Seu desempenho profissional conquista o respeito e a admiração da comunidade médica, assim como a amizade de seus pares. Essa fase ocupa todo um decênio. Durante ela, cedo consegue estabelecer o estudo do LCR como uma das especialidades da neurologia e, em 1929, inicia as atividades do seu próprio laboratório especializado em exames de LCR. Cientificamente, essa fase se abre com sua Tese de Doutoramento sobre basedowismo frustro e a publicação sobre a espondilite rizomélica, estudo com Vampré, com quem igualmente publica os resultados de seus primeiros estudos sobre o LCR. Seguem-se outras publicações sobre a matéria resultantes de suas investigações, coroadas com o primeiro livro brasileiro sobre o tema ("O liquido cefalo-raquidiano em clinica". São Paulo: Melhoramentos, 1938). O principal tema de suas pesquisas nessa fase é o estudo conjugado do LCR e das moléstias infecciosas do sistema nervoso central e seus envoltórios, com destaque à neurossífilis e à neurocisticercose. Caracteriza a síndrome liquórica da cisticercose encéfalo-meníngea (1936). Detalha o comportamento do LCR na neurossífilis pré-clínica, assunto que deu origem à sua tese de Livre Docência, concurso que presta em 1938 na FMUSP. Nesta, é o primeiro Livre Docente de Neurologia por concurso de títulos e provas.

Com a prematura morte de Vampré em 1938, Tolosa, Longo e Lange lutaram para que a escola do pranteado mestre permanecesse una. Juntos permaneceram e juntos decidiram. Tolosa conquistou por concurso a Cátedra de Neurologia da FMUSP. Longo, por igual concurso, conquistou a Cátedra de Neurologia da Escola Paulista de Medicina (EPM), que iniciava seus passos e que prematuramente também perdera nesse mesmo ano seu primeiro professor encarregado do ensino da neurologia, Fausto Guerner. Lange, o mais jovem dos três, permaneceu na Clínica Neurológica da FMUSP como o Chefe de Clínica. Nessa nova fase de sua vida científica dá con- 
tinuidade à publicação de resultados de estudo sobre o LCR e publica estudos clínicos. Inaugurando estes últimos, desenvolve os estudos sobre "O valor semiótico da prova dos braços estendidos" e sobre "Sinais piramidais nos membros superiores", com os quais conquista os dois prêmios da Associação Paulista de Medicina (APM), em 1940: o Prêmio Honorio Libero e o Prêmio Enjolras Vampré. À publicação deles, seguem-se as de outros, frutos de sua atividade na Clínica e no ensino da neurologia.

Na invejável posição de Chefe de Clínica, que tanto honrou, deu tudo de si para o progresso da Clínica Neurológica da FMUSP como um todo, e de cada uma de suas especialidades à medida em que estas surgiam. Exerceu essa função com maestria, brilho e brio até se aposentar aos sessenta e dois anos de idade, em 1965, no regime de tempo integral e dedicação exclusiva, do cargo de Professor Associado que sete anos antes conquistara por concurso.

Sem exageros, sua atuação como Chefe de Clínica é o modelo ideal para os que o sucederam nessa função, alvo esse até hoje não atingido. Tomava a si a responsabilidade de orientar os integrantes e os estagiários da Clínica. Fazia deles seus discípulos e os conduzia com rigor e eficiência. Dos seus discípulos diretamente ligados à FMUSP, dez concluíram o Doutoramento em regime de tutorado, nove conquistaram por concurso o grau de Docente Livre e três, a posição de Professor Titular de Neurologia na própria FMUSP. Igual era sua atenção para com os estagiários, vindos de outros centros. Cuidava deles para que soubessem erigir em seus ambientes de trabalho uma sadia prática neurológica e, depois de concluído o estágio, continuava a acompanhar e a orientar suas carreiras. Simbolicamente, reforçando suas lições, a eles entregava um martelo de reflexos e o um diploma, o Diploma da Ordem do Martelo. De início, este era visto como um estímulo; com o tempo, como um almejado prêmio. Assim, fez do discípulo um amigo e era a ele a quem primeiro recorriam os discípulos quando de um conselho sensato ou de um momento difícil. Toda essa amizade cercou o carinho com que seus discípulos lhe conferiram, ao aposentar-se o Diploma de Grão-Mestre da Ordem do Martelo.

Em 1983, a Congregação da FMUSP, em sessão solene, ao Prof. Dr. Oswaldo Lange confere sua mais alta distinção, a medalha Arnaldo Vieira de Carvalho.

\section{OSWALDO LANGE E SOCIEDADES \\ MÉDICAS: APM E ABN}

O Dr. Oswaldo Lange sempre incluiu o desempenho do médico frente a seus colegas como parte integrante da atividade profissional. Sua atuação na APM e na Academia Brasileira de Neurologia (ABN) dão medida de seu ângulo de visão a propósito desse desempenho.

De 1947 a 1955, alinhou-se com seu companheiro e amigo, Jairo Ramos, para com outros colegas lutar pelo objetivo de fazer da APM uma sociedade realmente voltada à medicina e que tivesse projeção estadual e não apenas local, na cidade de São Paulo. O sucesso alcançado levou a que naturalmente se ampliassem as fronteiras da APM para todo o Estado de São Paulo e, depois, fortalecesse a idéia de constituir uma sociedade que reunisse os médicos brasileiros, levada a cabo por Jairo Ramos e tantos outros e de que resultou a criação da Associação Médica Brasileira (AMB), em 1951. Na APM, Jairo Ramos e ele capitanearam a remodelação dos Departamentos Científicos, dando-lhes vida e desígnio. Promoveram congressos e jornadas que encontraram seu ponto mais alto em 1954, por ocasião do quarto centenário da cidade de São Paulo, quando a APM patrocinou quatorze congressos. Entre estes, destaca-se o XIX Congresso Internacional de Oto-NeuroOftalmologia que contou com figuras de renome mundial, muitas daquelas da neurologia comparecendo graças particularmente ao prestígio internacional que Oswaldo Lange a essa época já granjeara. Dentro dos mesmos propósitos de construir com seriedade, Lange assumiu o periódico da APM - a Revista Paulista de Medicina - para o qual estabelece rumos verdadeiramente científicos, para tanto arduamente trabalhando como seu Editor (1947-1955).

No início dos anos 60, a idéia de criar uma sociedade neurológica de âmbito nacional se fortalecera, graças aos esforços que levaram à criação da World Federation of Neurology (WFN), em Bruxelas, em 1957, sob a presidência de Ludo van Bogaert e tendo Macdonald Critchley como vice-presidente. Longo e Lange abraçaram a idéia, com tantos outros propugnando para que Deolindo Couto encabeçasse os esforços. E assim, em 1962, instala-se a ABN. Paulo Pinto Pupo e Lange redigem o primeiro estatuto da $A B N$, e esta se filia à WFN assim como à $A M B$, posteriormente (1971). Em 1966, Lange é eleito Delegado da $A B N$ junto à WFN, mandato que a Assembléia Geral da $A B N$ quadrienalmente renovou até 1978, quando não mais aceita ele a reindicação. Por doze anos consecutivos promoveu ele a neurologia brasileira. Graças aos seus esforços, a ABN recebeu e realizou, na cidade de São Paulo, o III Congresso Panamericano de Neurologia, em 1971. Participou ele de todas as reuniões do Conselho de Delegados da WFN bienalmente realizadas durante seu 
mandato, em New York, em Barcelona e em Amsterdam. Igualmente, participou das reuniões bienais dos congressos panamericanos, em San Juán (Porto Rico), em São Paulo e na cidade do México. Valendo-se do prestígio do cargo, sempre estimulou a $A B N$ ao cumprimento de seus compromissos para com a WFN e, desta, conseguiu o reconhecimento das neurociências brasileiras. Um dos mais preciosos resultados desse esforço em plano internacional, foi a escolha de colegas brasileiros como relatores de temas oficiais nos congressos oficiais da WFN, tanto nos panamericanos (São Paulo, México, Caracas) como nos mundiais (Barcelona, Amsterdam). Adicionalmete, compila as atas da $A B N$, que bienalmente publicou, a partir de 1962, como Apêndice de Arquivos de Neuro-Psiquiatria e que contêm um resumo da vida da nossa sociedade neurológica. Até o final de sua vida, com dedicação e com autoridade, faz-se um verdadeiro conselheiro de membros da agremiação, de seus dirigentes e de seu sucessor como Delegado da ABN junto à WFN.

Recebe em 1976 o título de Patrono da ABN. É igualmente o patrono do Grupo de Trabalho de LCR da ABN.

Tantos feitos enaltecem as lições de vida de Oswaldo Lange. No entanto, eles são um preâmbulo a emoldurar seu grande amor na medicina, a comunicação médico-científica. Ela desabrochou em sua maior realização - o periódico Arquivos de Neuro-Psiquiatria.

\section{OSWALDO LANGE E ARQUIVOS DE NEURO-PSIQUIATRIA}

Como em parte consta do editorial a propósito do sexagésimo aniversário de Arquivos de NeuroPsiquiatria (Dezembro, 2002) o trio dos sucessores de Vampré - Tolosa, Longo e Lange - decidiu atender à necessidade de criar um periódico para divulgar os frutos do labor científico "oriundos da bifurcação que resultou da vitalidade da árvore plantada por Enjolras Vampré" como escreveram Tolosa e Longo na qualidade de Professores Catedráticos de Neurologia, o primeiro da FMUSP e o segundo da EPM, apresentando o primeiro número da revista. Nesse texto escreveram ainda que determinaram unir seus esforços para prestigiar em todos os sentidos a nova publicação, que surge sob a direção de Lange, "a cujos esforços e perseverança se deve a transposição de inumeráveis obstáculos iniciais que dificultam, quando não impossibilitam, entre nós, uma realização desta natureza. Foi, sem dúvida, à sua tenacidade, alimentada pela certeza de servir a um elevado ideal que se deve sua publicação". Assim, vaticinaram eles o futuro do periódico levando em conta os traços de personalidade do colega dentre eles escolhido e por eles integralmente apoiado para levar avante tão grande empenho, Oswaldo Lange. $\mathrm{Na}$ realidade, apenas entreviram o futuro.

Cumpridas as exigências legais e vencidas as primeiras etapas, em junho de 1943 vem a lume o primeiro número de Arquivos de Neuro-Psiquiatria. Nos moldes do que anteriormente publicara a propósito da biografia do Professor Enjolras Vampré, abre o número a homenagem que ele presta à memória de seu mestre. Em dezembro de 1943, ao término do Volume 1, em nota editorial a propósito da tarefa que se impôs, Lange escreve: " não podemos falhar. Através de quaisquer óbices, levaremos a cabo a tarefa. Faremos de Arquivos de Neuro-Psiquiatria uma publicação que possa ombrear com as melhores nacionais e que se equivalha às congêneres de países nos quais, pela excelência e volume de publicações, a neuro-psiquiatria parece ter chegado a um nível mais alto. Faremos jus à confiança que em nós está sendo depositada. E, principalmente, Arquivos de Neuro-Psiquiatria será um órgão editado em São Paulo para servir todo o Brasil.".

Desde então, prestigiado por seus discípulos e sempre apoiado pela sua família, muitas vezes valendo-se de recursos financeiros próprios, Lange dá vida ao periódico. Mantém absolutas a sua regularidade e a sua periodicidade. Editora com rigor cada artigo e faz do autor um aluno de redação de artigo científico. Estabelece a linha editorial e as normas de publicação, que mantém sempre atualizadas. Insere notícias sobre fatos e dados da neurologia brasileira, paulatinamente abrindo o horizonte de Arquivos. Igualmente, noticia dados da neurologia latino-americana e com suas revistas estabelece permuta. Envia o periódico também para centros neurológicos de outros países. Por permuta ou por doação propicia a divulgação e o conhecimento da revista, consolidado quando da sua escolha como o veículo da homenagem científica internacional ao Prof. Dr. Luís Barraquer Ferré, eminente mestre da neurologia de Barcelona e pedra angular da neurologia espanhola, que foi coordenada por outro grande neurologista, Robert Wartenberg, a essa altura já sediado nos Estados Unidos, em San Francisco. Esse número aparece em junho de 1952, apresentado pelo seu Editor. Para esse número colaboraram com estudos originais muitos dos luminares da neurologia mundial e, a partir dele, isto se tornou uma tônica.

Tudo isso foi ampliando a penetração do periódico e garante o credenciamento dele como órgão oficial de divulgação científica da ABN, por esta aprovado pela unanimidade dos participantes da Assem- 
bléia Geral de Porto Alegre, em julho de 1970. Registra esse fato logo a seguir, no número de setembro desse ano. Cedo a revista é catalogada pelo Index Medicus. Após, em outros centros de catalogação e de indexação, entre eles os da WHO, da BIREME, do LILACS e, em plano nacional, o do IBICT.

Em 1962, a revista completa vinte anos e, em editorial, Lange salienta a regularidade absoluta de sua publicação e a manutenção das características gerais da revista, e apresenta o primeiro Índice Remissivo, que vem a lume como Apêndice do número de dezembro desse ano. Em 1982 a revista completa quarenta anos e o exemplar de dezembro inclui o anúncio ao Índice Geral de 40 Anos e vale reproduzir o que escreveu, deste seu gigantesco esforço: "Comemorando a passagem dos 40 anos de atividade da revista, Arquivos de Neuro-Psiquiatria publicará, possivelmente em junho-1983, o índice geral do que foi publicado nestes 40 anos. É a primeira vez que uma revista médica latino-americana publica índice abrangendo todo esse tempo. Naturalmente, trabalho de tal monta não pode ser feito por uma só pessoa. Assim, agradeço em primeiro plano o valioso auxílio prestado pelo Prof. Horacio Martins Canelas que elaborou todos os 40 índices anuais tornando possível a edição do índice geral que o Editor ajuntou dando a ordenação alfabética. Todo o material foi depois datilografado em fichas, perto de 5000 fichas, que foram depois reordenadas mediante exaustivo trabalho de ordenação feito carinhosamente por minha neta, Sra. Adriana Spina França Machado que, em seguida, controlou o serviço de impressão tipográfica feita com esmero pela Gráfica Sangirardi Ltda. A revisão final foi feita por minha filha, Sra. Marília Lange Spina França. A todos que colaboraram diretamente na elaboração e feitura deste Índice Geral de 40 anos deixo consignados os meus agradecimentos pela realização que constitui um excelente presente para os leitores da revista.". A notícia é republicada em março de 1983, quando esse índice geral vem a lume. Ele é um monumento à dedicação dada a Arquivos de Neuro-Psiquiatria por Oswaldo Lange, seu Editor.

Como Editor, Lange reserva o espaço da revista para contribuições de cunho científico e técnico. Só raramente insere matéria de sua autoria. Seus dois companheiros, Longo e Tolosa, são o motivo de dois desses textos. Em 1967 aparece a homenagem à memória de Paulino Longo. Em 1969, a homenagem a Adherbal Tolosa, quando de sua aposentadoria compulsória. Seu último escrito aparece em dezembro de1985: “Em 4 de julho de 1985, dia do centenário do nascimento do Prof. Dr. Enjolras Vampré, em cerimônia singela mas de profundo conteúdo emocional - patrocinada pela Faculdade de Medicina da Universidade de São Paulo - e promovida pelo Diretor de seu Museu, o Prof. Dr. Carlos da Silva Lacaz - o Prof. Dr. Horacio Martins Canelas pronunciou tocante oração, comemorando o evento. Arquivos de Neuro-Psiquiatria, homenageando com este número o llustre Mestre, transcrevem a oração feita por Canelas." Esta sua última mensagem relembra aquele que foi seu mestre e seu paradigma. Curiosamente, foi sobre Vampré o texto de abertura da revista que escrevera em 1943 e que assim termina: "Reverenciando a memória de Enjolras Vampré, os que se encarregaram de fundar e dirigir esta revista prometem fazer tudo o que estiver ao seu alcance para não desmerecer a aprendizagem que tiveram e continuar no rumo que Ihes foi traçado.". E assim fez; e assim preparou seus continuadores. Tendo perdido a visão, continua à frente da revista até quando, em 29 de agosto de 1986, cessam seus dias. Seu último ato foi aprovar, dois dias antes, o conteúdo final do último número (Dezembro) do Volume 44. Seguindo seus ditames quanto à melhor forma de homenagear alguém, expressos nas duas ocasiões lembradas em que foi homenageado em vida (1956 e 1965), seus discípulos e amigos da Clínica Neurológica da FMUSP cultuam sua memória dedicando a ele toda a produção científica que aparece no número de março do ano seguinte. Homenagem, conceituava Oswaldo Lange, é edificar, é o assumir responsabilidades, é o dever cumprido, é o trabalho executado com disciplina e galhardia. A continuação de Arquivos de Neuro-Psiquiatria como foro científico-tecnológico que mantém a seriedade e os rumos por ele estabelecidos, é a melhor homenagem ao seu trabalho, à sua vida.

O Dr. Oswaldo Lange preparou seus colaboradores editoriais entre seus discípulos. Eles estão entre os que, quando da sua morte, estabeleceram a associação sem fins lucrativos que continua a publicar a revista - a Associação Arquivos de Neuro-Psiquiatria Dr. Oswaldo Lange. Os membros da associação, em equipe, com o respaldo da $A B N$, procuram manter, atualizada, firme e forte, a maior das contribuições de Oswaldo Lange para a neurologia pátria - Arquivos de Neuro-Psiquiatria.

Este apanhado estaria incompleto se aqui terminasse. Importa salientar sua contribuição como Editor: ela é uma preciosa lição para os cultores das neurociências que se voltam à produção de revistas da área.

OSWALDO LANGE, O EDITOR

A política editorial do Dr. Oswaldo Lange tem seu alicerce no que Morris Fishbein corporificou para a 
American Medical Association (AMA), graças a sua experiência como Editor do Journal of the American Medical Association (JAMA). Em 1944, o Dr. Lange vai a Chicago para complementar seu conhecimento diretamente com Morris Fishbein, a quem, depois, em 1947, recebe em São Paulo quando da visita dele à América Latina como Editor do JAMA e organizador do Quarterly Cumulative Index Medicus. Os ensinamentos desse luminar refletiram-se na reestruturação que Lange fez na Revista Paulista de Medicina, da APM, e na assessoria editorial que nessa mesma época ele deu à Revista de Medicina, publicada pelo Centro Acadêmico Oswaldo Cruz, dos alunos da FMUSP. Mas é em Arquivos de Neuro-Psiquiatria que os conhecimentos adquiridos pelo Dr. Lange se revelam por inteiro, e amadurecem.

Oswaldo Lange, aos poucos, desenvolve sua própria visão editorial. Para tanto, seu foro é a seção de "Notícias e Comentários" de Arquivos de Neuro-Psiquiatria. A propósito do conteúdo de um artigo científico, publica sucessivos textos e que, com o progredir de sua experiência editorial, são reavaliados entre 1965 e 1970.

Na mesma seção, "Notícias e Comentários", publica periodicamente relatórios sobre a administração da revista acompanhados de suas reflexões acerca do assunto. Em 1974, registra que nessa ocasião a revista tinha 610 assinantes, 558 no Brasil e 52 no estrangeiro, somando as remessas gratuitas 83 para o estrangeiro e 7 para o Brasil. Compara esses números àqueles relatados por John N. Walton, na época editor do Journal of the Neurological Sciences, com tiragem de 1000 exemplares e 960 assinantes. Lembra que poderia parecer despropositado e até certo ponto exibicionista o relato desses números e que essas minúcias visam a comprovar a distribuição real da revista, o que constitui uma informação básica para contrapor o que vem sendo feito em Arquivos de Neuro-Psiquiatria ao que vem sendo rotulado em diversas revistas brasileiras como "distribuição controlada" ou "distribuição rígida", expressões que nem sempre representam a realidade. Introduz um ponto de vista essencial, que segue: "Quando em 1944, isto é, um ano depois da fundação de Arquivos de Neuro-Psiquiatria, fiz demorada visita ao Departamento Editorial da AMA, no qual eram editados, além do JAMA, mais 10 "Archives" especializados e opúsculos para a educação médico-preventiva popular, aprendi com Morris Fishbein - o EditorChefe das publicações da AMA naquela época - que para ser conceituada como boa perante os leitores e entidades internacionais, uma revista deve obedecer a três itens básicos, como sejam a regularidade e pontualidade na publicação, a uniformização gráfica e na apresentação dos trabalhos publicados e the last but not the least - a não inclusão de anúncios ou encartes dentro do texto científico. Nas conversas com Morris Fishbein aprendi também que a distribuição gratuita de revistas médicas deve ser restringida ao mínimo possível, para benefício dos autores de trabalhos científicos e para a valorização da revista aos olhos de seus leitores. Veio à baila este tópico relativo à gratuidade da remessa de revistas quando vim a saber que a AMA tinha, naquele longínquo ano de 1944, cerca de 158000 associados, ao passo que a tiragem do JAMA era de apenas 110000 semanalmente. Explicou Morris Fishbein que o fato de ser alguém associado da AMA não implicava no direito ao recebimento gratuito da revista cujas assinaturas eram pagas à parte. Assim, dos associados da AMA só recebiam a revista os que pagavam a assinatura; aliás, nem era obrigatório o ingresso na AMA para a assinatura da revista. Além de antieconômica, disse Morris Fishbein, a distribuição gratuita desvaloriza a revista perante os organismos internacionais e mesmo perante seus leitores, pois revistas dadas nem sempre são valorizadas como as adquiridas.". E continua: "Desde essa época tenho procurado seguir, à risca, os conselhos que recebi. As remessas gratuitas que eram vultosas (cerca de 2/3 da tiragem) nos primeiros anos de publicação de Arquivos de Neuro-Psiquiatria, o que era justificado pela necessidade de difundir a revista tanto no Brasil como no estrangeiro, foram sendo reduzidas paulatinamente. Hoje, no Brasil, pessoa alguma recebe a revista de graça, nem mesmo seus editores, redatores e revisores, nenhum dos quais é remunerado. Tais remessas, como o demonstram as listas publicadas no exemplar Junho-1974, se limitam aos Diretores e a alguns Delegados da Federação Mundial de Neurologia, a revistas médicas da mesma especialidade com as quais foi estabelecida permuta e a entidades internacionais visando à indexação e difusão dos trabalhos publicados.". Em dezembro do mesmo ano, volta ao tema, atualiza os números - tiragem 800 exemplares; assinantes 652; remessas gratuitas 99 (Delegados da WFN 24, permuta 31 , instituições indexadoras 10 , bibliotecas 34) - e encerra o assunto relembrando que "o trabalho de editoração de uma revista brasileira especializada que insiste em manter normas de alto padrão e que não pode se dar ao luxo de manter numerosos empregados e redatores remunerados, não se limita à leitura severa dos trabalhos enviados para publicação, fazendo sugestões para melhorar e uniformizar a apresentação do conteúdo científi- 
co. A base econômica tem de ser também cogitada e atendida tanto pelo corpo editorial, no qual ninguém é remunerado nem mesmo recompensado pelo recebimento gratuito da revista, como pelos assinantes, em um trabalho de conjunto para a manutenção do padrão de publicação e para sua plena aceitação nos meios científicos nacionais e estrangeiros". E acrescenta, em março de 1975: "Neste modo de proceder - isento de qualquer intenção comercial ou lucrativa como vem sendo demonstrado nos comentários que estamos fazendo - Arquivos de Neuro-Psiquiatria nada mais faz do que seguir exemplos dados pelas boas revistas especializadas e de alto padrão publicadas em países em pleno desenvolvimento, pois nenhuma delas é distribuída, gratuita e indiscriminadamente, a bibliotecas de escolas médicas, especialmente as sediadas em seus próprios países de origem. Algumas destas revistas até cobram preços mais elevados para assinaturas de bibliotecas do que para assinaturas pessoais, realismo que nos parece exagerado.".

Todas essas considerações alicerçam sua visão do trabalho editorial, que encerra como segue, na mesma seção do periódico, em 1975 (pgs 187-189): “O processo de informação em Medicina, como em qualquer outro ramo de atividade, compreende várias fases - estruturação e elaboração, publicação e disseminação, indexação e arquivamento - constituindo uma cadeia cujos elos, embora executados por diversas pessoas e em lugares diferentes, devem ser bem entrelaçados. Cabe aos autores a maior parcela de responsabilidade na eficiência deste processo informativo, de vez que seus trabalhos, constituindo o ponto de partida para o andamento processual subsequente, devem ser bem estruturados e elaborados corretamente para facilitar a impressão tipográfica e, depois, a catalogação e a indexação.".

Passo seguinte, também em 1975, vem a lume na mesma seção do periódico (pgs 297-300) seu experiente conselho a propósito da ética da publicação de artigos. Este guia é ditado por sua experiência editorial e tem doze itens precisamente redigidos:

1 só publicar trabalhos que contenham algo de novo como informação ou alguma mensagem útil como contribuição a assunto já conhecido;

2 evitar publicar trabalhos visando ao mero aumento de currículo para competição de títulos ou apenas para assegurar a continuidade de ajudas financeiras sob forma de bolsas de estudo;
3 não publicar algo visando apenas promoção pessoal ou como fonte de renda sustentada por laboratórios farmacêuticos;

4 ser exato no referir dados, sejam próprios ou de outros autores;

5 não publicar, dando idéia de segurança, dados sobre cuja validade não está seguro;

6 não copiar expressões escritas por outros e transmiti-las como se fossem suas; a simples alteração na construção da frase não exime da responsabilidade de indicar quem é o verdadeiro autor; usar aspas quando transcrever trechos integrais de outros autores;

7 não referir, dando idéia de ter lido na íntegra, trabalhos dos quais conheça apenas o resumo;

8 só reproduzir ilustrações de trabalhos alheios depois de obter o consentimento do autor e do editor da revista onde foram publicados originalmente;

9 não permitir que seu nome figure na co-autoria de um trabalho, a menos que tenha contribuído realmente - como orientador ou como cooperador e, neste caso, participar efetivamente da redação do trabalho;

10 agradecer - em notas de rodapé ou no fim do trabalho - os auxílios recebidos de terceiros sob forma de ajuda material, apoio moral, críticas construtivas, sugestões para a redação, compilação da bibliografia;

11 redigir o texto do trabalho em boa linguagem científica, isto é, com precisão, concisão e clareza, sem rebuscamentos literários ou verbosidade;

12 submeter o trabalho à crítica de pessoa mais experimentada; isto é obrigatório quando o autor faça parte integrante de instituição ou Serviço cujo nome ficará ligado à publicação.

Hoje, mais de um quarto de século além, esses conselhos continuam inteiramente válidos. Eles são o melhor modo de concluir esta visão panorâmica de um criador de escola e daquilo que de melhor criou: o Dr. Oswaldo Lange e o periódico Arquivos de Neuro-Psiquiatria. Tal como ele ensinou a honrar a escola neurológica a que pertencemos, em nome dessa mesma escola e com toda a equipe do periódico, apresento o Volume 61, dedicado ao centenário do seu sempre Editor Fundador, o Prof. Dr. Oswaldo Lange.

ANTONIO SPINA-FRANÇA Editor Executivo 